\section{Encuentro de \\ Cine Documental Santa Fe 2017}
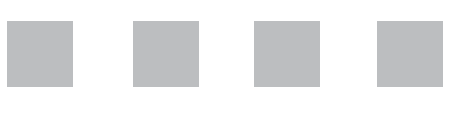
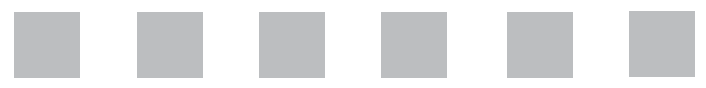

\section{- Viernes 10 de diciembre}

17 hs. Proyección de HITCHCOCK/TRUFFAUT, 2015, 80 minutos, de Kent Jones, guión de Serge Toubiana.

Este documental cuenta la historia de la relación de Alfred Hitchcock con François Truffaut, y más precisamente la historia del libro «El cine según Hitchcock», imprescindible para todo interesado en cine.

\section{Mesa sobre los libros de cine}

Participantes: Nicolás Zukerfeld, Bárbara Peleteiro, Marilyn Contardi, Juan Novak, Rodrigo Moreno, Malena Solar.

20 hs. Proyección LA EXPERIENCIA BLOCHER, 2013, 100 minutos, de Jean-Stéphane Bron.

Bron acompaña en sus viajes de campaña a Christoph Blocher, político suizo de extrema derecha muy popular, y al mismo tiempo nos cuenta, como nunca se había contado antes, la vida de un hombre político.

\section{- Sábado 2 de diciembre}

17 hs. Proyección UNA CIUDAD DE PROVINCIA, 2017, 88 minutos, de Rodrigo Moreno.

En Colón, la ciudad entrerriana, se instala Rodrigo Moreno y desde allí despliega su mirada sobre la gente y sobre el cine mismo.

Presentación del libro Santa Fe ciudad set, del № 11 de los Cuadernos de Cine documental y del № 4 de la Revista de cine.

Participantes: Rodrigo Moreno, Malena Solarz, Patricio Agusti, Agustín Falco. Coordinación: Juan Novak.

20 hs. Proyección IN JACKSON HEIGHTS, 2015, 185 minutos, de Frederick Wiseman.

El barrio de Nueva York, multicultural, pluriétnico, donde se concentra una gran población de habla hispana, visto por uno de los grandes documentalistas actuales. 
Una ciudad de provincia |

La Experiencia Blocher |

In Jackson Heights |
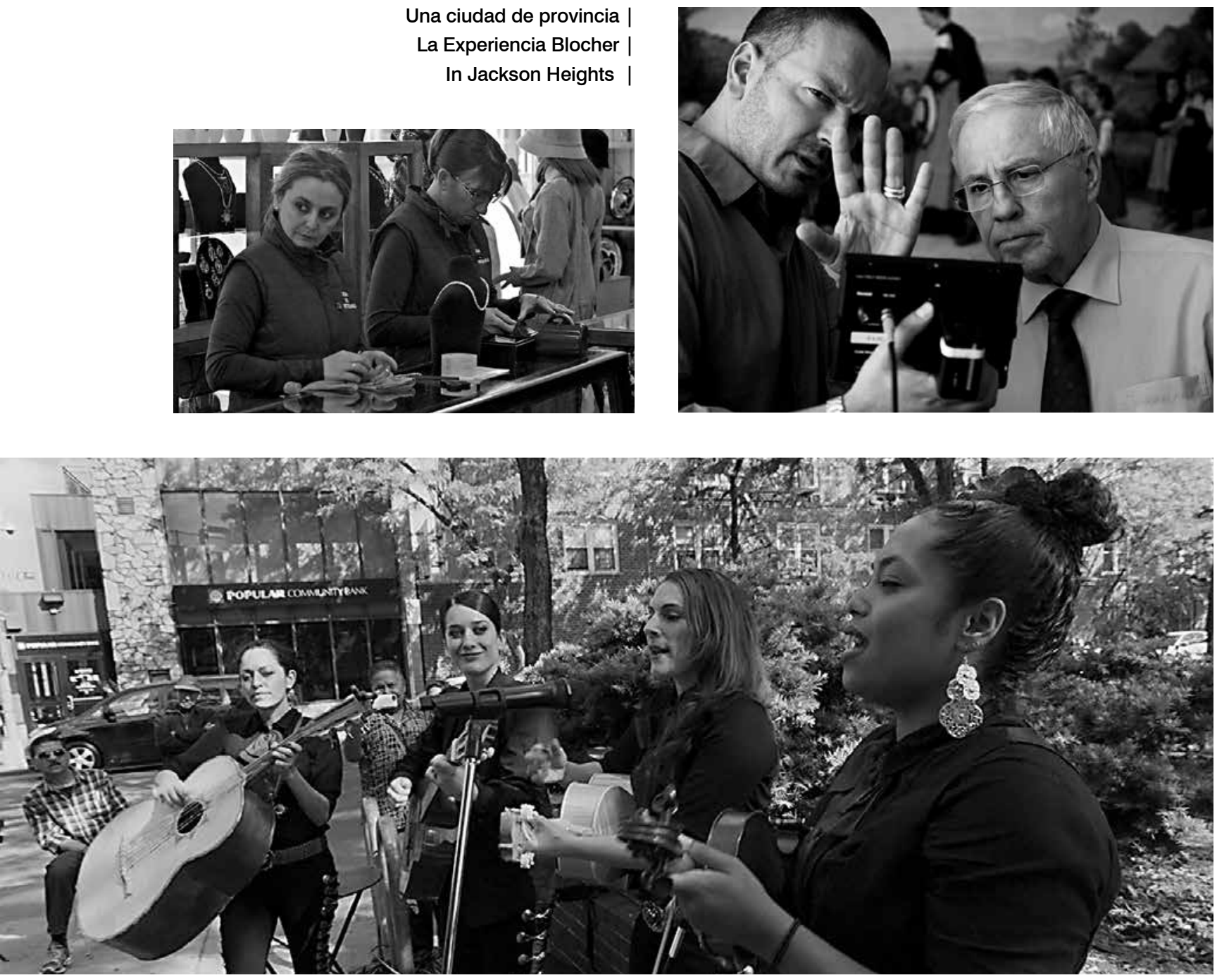